\title{
Amyloid- $\beta$ and Alzheimer's disease type pathology differentially affects the calcium signalling toolkit in astrocytes from different brain regions
}

\author{
AA Grolla ${ }^{1,2}$, JA Sim², D Lim ${ }^{1}$, JJ Rodriguez ${ }^{3,4}$, AA Genazzani ${ }^{1}$ and A Verkhratsky ${ }^{\star 2,3,4}$
}

The entorhinal-hippocampal circuit is severely affected in Alzheimer's disease (AD). Here, we demonstrate that amyloid- $\beta$ (A $\beta)$ differentially affects primary cultured astrocytes derived from the entorhinal cortex (EC) and from the hippocampus from nontransgenic controls and 3xTg-AD transgenic mice. Exposure to $100 \mathrm{nM}$ of $\mathrm{A} \beta$ resulted in increased expression of the metabotropic glutamate receptor type 5 (mGluR5) and its downstream $\operatorname{lns}_{3}$ receptor type 1 (InsP $R$ R1) in hippocampal but not in EC astrocytes. Amplitudes of $\mathrm{Ca}^{2+}$ responses to an mGluR5 agonist, DHPG, and to ATP, another metabotropic agonist coupled to Ins $P_{3} R$, were significantly increased in $A \beta$-treated hippocampal but not in EC astrocytes. Previously we demonstrated that senile plaque formation in 3xTg-AD mice triggers astrogliosis in hippocampal but not in EC astrocytes. The different sensitivities of the $\mathrm{Ca}^{2+}$ signalling toolkit of EC versus hippocampal astrocytes to $A \beta$ may account for the lack of astrogliosis in the EC, which in turn can explain the higher vulnerability of this region to $A D$.

Cell Death and Disease (2013) 4, e623; doi:10.1038/cddis.2013.145; published online 9 May 2013

Subject Category: Neuroscience

Neuroglia are homeostatic cells of the central nervous system, which are ultimately involved in many (if not all) forms of neuropathology. ${ }^{1,2}$ The pathological potential of neuroglial cells was recognized already by Rudolf Virchow, who comprehended that neuroglia 'is one of the most frequent seats of morbid change'. ${ }^{3}$ Pathologically remodelled glial cells associated with various types of neurological conditions have been subsequently identified by prominent histopathologists such as Nissl, Frommann and Alzheimer (see Kettenmann and Verkhratsky ${ }^{4}$ for a historical review). Alzheimer ${ }^{5}$ made the first descriptions of pathological glia in the context of dementia and identified glial cells as morphological components of senile plaques.

Astrocytes are the principal homeostatic cells of the central nervous system. The role of astroglia in the pathogenesis of Alzheimeŕs disease (AD) remains generally unknown although the interest in astroglial remodelling in the course of neurodegeneration has increased substantially during the last decade. ${ }^{1,6-9} \mathrm{AD}$ is considered to be one of the most prevalent forms of dementia in humans, ${ }^{10}$ the symptoms of which are manifested by progressive cognitive impairment. Histopathological changes associated with AD include senile plaques, neurofibrillary tangles, neuroinflammation, altered synaptic connectivity and neuronal death. ${ }^{11,12}$ The loss of synapses, in particular, is considered to be the earliest AD-associated cellular pathology responsible for early signs of cognitive failure. ${ }^{13,14}$ This loss of synapses may reflect functional downfall of astrocytes that are generally responsible for synaptic maintenance and homeostasis of ions and neurotransmitters, the latter being critical for synaptic transmission. Indeed, recent data indicated atrophic changes in astroglia at the early (i.e., pre-plaque) stages of AD-like pathology in transgenic model animals, which may account for the deficient synaptic connectivity. ${ }^{9,15,16}$ At the later stages, the emergence of $\beta$-amyloid depositions and formation of senile plaques trigger reactive astrogliosis, which mainly occurs in cells directly associated with $\beta$-amyloid plaques. ${ }^{15,16}$

The spatio-temporal progression of $A D$ is well identified, with the entorhinal cortex $(E C)$ being the very first area to be affected by the pathology. ${ }^{17}$ Neurons in superficial layers of the EC innervate all hippocampal subregions, including the dentate gyrus (DG), CA3, CA1 and subiculum via the perforant pathway; synaptic connections between mossy fibers of DG and CA3 neurons and Schaffer collaterals from CA3 to CA1 neurons complete the forward hippocampal circuit. $^{18}$ In $A D$, a significant loss of neurons in EC layer II

\footnotetext{
${ }^{1}$ Dipartimento di Scienze del Farmaco, Università degli Studi del Piemonte Orientale 'Amedeo Avogadro', Novara 28100, Italy; ${ }^{2}$ Faculty of Life Sciences, University of Manchester, Manchester M13 9PL, UK; ${ }^{3}$ IKERBASQUE, Basque Foundation for Science, 48011, Bilbao,, 48011, Bilbao, Spain and ${ }^{4}$ Department of Neurosciences, University of the Basque Country UPV/EHU \& CIBERNED, 48940 Leioa, Spain

${ }^{*}$ Corresponding author: A Verkhratsky, Faculty of Life Sciences, The University of Manchester, Michael Smith Building, Oxford Road, Manchester M13 9PL, UK. Tel: +44 (0)161 2755414; Fax: 44 (0)161 2755463; E-mail: Alexej.Verkhratsky@ manchester.ac.uk

Keywords: astrocytes; Alzheimer's disease; entorhinal cortex; hippocampus; calcium deregulation; amyloid- $\beta$

Abbreviations: 3xTg-AD, triple transgenic mouse model of $A D ; A D$, Alzheimer's disease; $A \beta$, amyloid- $\beta$; ANOVA, analysis of variance; APP, amyloid precursor protein; ATP, adenosine triphosphate; CA1, CA3, Cornu Ammonis areas 1, 3; DG, dentate gyrus; DHPG, (S)-3,5-dihydroxyphenylglycine; DIV, days in vitro; DMEM, Dulbecco's modified Eagle's medium; DMSO, dimethyl sulfoxide; EC, entorhinal cortex; EDTA, ethylenediaminetetraacetic acid; FBS, fetal bovine serum; GFAP, glial fibrillary acidic protein; HEPES, 4-(2-hydroxyethyl)-1-piperazineethanesulfonic acid; $\operatorname{InsP}_{3} \mathrm{R} 1$, InsP ${ }_{3}$ receptor type 1; KRB, Krebs-Ringer modified buffer; mGluR5, metabotropic glutamate receptor type 5; NA, numerical aperture; PBS, physiological buffer saline; SDS-PAGE, sodium dodecyl sulfate polyacrylamide gel electrophoresis Received 02.2.13; revised 09.3.13; accepted 03.4.13; Edited by G Melino
} 

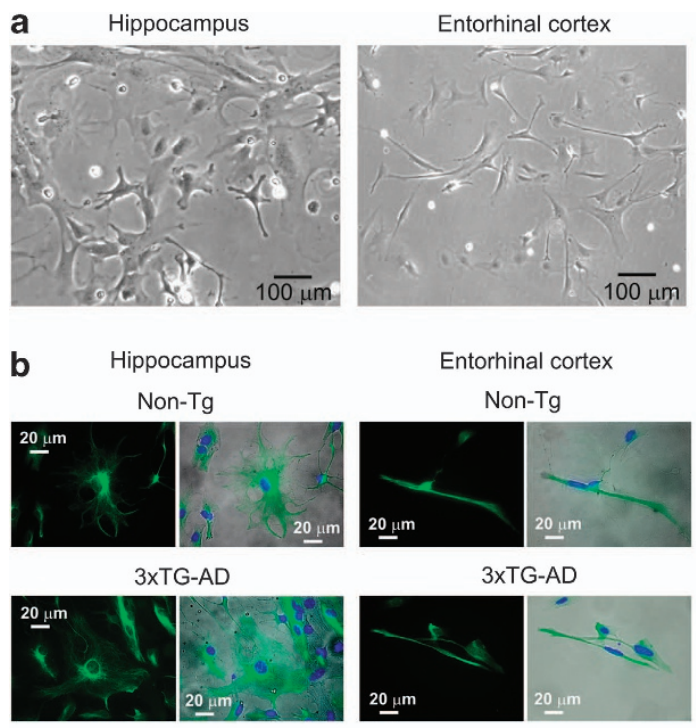

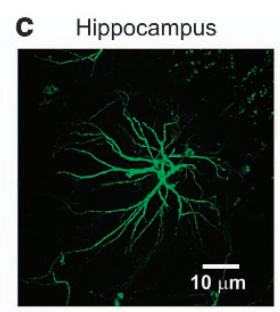

Entorhinal cortex

d

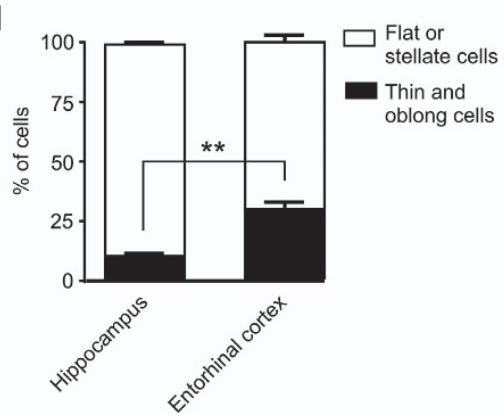

Figure 1 Morphological differences between cultured astrocytes derived from EC and hippocampus. (a) Microphotographs show the phase-contrast images of live (non fixed) hippocampal cultured astrocytes (left) and EC cultured astrocytes (right) at 4 days in vitro. (b) Representative images of GFAP-stained hippocampal and EC astrocytes derived from non-Tg control and 3XTg-AD model animals. Left panels represent images of GFAP immunofluorescence of stained cells, whereas right panels show merged images of phase-contrast images (gray) and GFAP/DAPI (green/blue) staining obtained from the same cells and fields of view. (c) In situ images of GFAP-stained hippocampal and EC astrocytes; the cells were GFAP labelled in slices obtained from 6-month-old non-Tg animals. For technical details, see Olabarria et al. ${ }^{15}$ and Yeh et al. ${ }^{22}$ (d) Quantification of the percentage of thin, long needle-shaped and flat or stellate cells in cultures prepared from hippocampus and the EC; $n=320$, from four different cultures ${ }^{*} P<0.01$

occurs at the early stages. ${ }^{19}$ In AD patients, the EC could be the region from which the pathological process spreads towards other brain regions; this has been initially hypothesized because expression of APP, the precursor of $\beta$-amyloid, was higher in EC layer II neurons than in other brain areas. ${ }^{20}$ Moreover, APP synthesized by EC neurons is transported via the perforant pathway to presynaptic terminals in DG. A profound reduction in $\beta$-amyloid burden was observed in DG, following unilateral severance of the perforant pathway. ${ }^{21}$

Our previous morphological analysis ${ }^{22}$ found a remarkable difference in the AD-associated behavior of astrocytes in the EC. In contrast to the hippocampus, where reactive astrocytes were a prominent feature of $\beta$-amyloid depositions, in EC astrocytes failed to show any reactivity and were not specifically associated with $\beta$-amyloid. In this study, we analyzed $\mathrm{Ca}^{2+}$ signalling and the metabotropic $\mathrm{Ca}^{2+}$ signalling molecular toolkit in EC and hippocampal astrocytes in vitro in cell cultures. We found that these astroglial populations have distinct reactions to $\beta$-amyloid treatment that may account for differences in their reactivity in the pathological context.

\section{Results}

Astroglial cultures derived from the EC and hippocampus are morphologically different. The morphology of astroglial cells from the EC and hippocampus, when maintained in vitro for the first 3-5 days, was characteristically different. In hippocampal cultures, majority of the cells were large and flat (or star-shaped), whereas in EC cultures many cells were thin and oblong with almost needle-like morphology. Figure 1a shows the differences in morphology between cultured astrocytes derived from the hippocampus and astrocytes derived from the EC. Both types of cells were positive to glial fibrillary acidic protein (GFAP) immunostaining, confirming thus their astroglial nature (Figure 1b). The morphology of EC astrocytes maintained in culture was similar to their appearance in situ (Figure 1c). ${ }^{22}$ The quantification of the number of thin and oblong cells shows a significantly higher percentage of this morphological profile in EC cultures (Figures 1a, b and d). The overall morphological features of astrocytes from non-Tg and $3 \times T$ Th-AD mice did not show any significant differences (Figure 1b).

Of interest, in older cultures, we also observed different proportions of large flat 'proliferating' cells and star-shaped 'reactive' cells (expressing high levels of GFAP) in hippocampal versus EC cultures, the number of 'reactive' astrocytes being substantially higher in the former (the \% of star-shaped cells in hippocampal cultures was $21.3 \pm 3.07$, whereas that in EC cultures was $9.65 \pm 2.05, P<0.05 ; n=240$ cells from four cultures).

A $\beta$ oligomers differentially affect the expression of mGluR5 and Ins $\mathrm{P}_{3} \mathrm{R} 1$ in astrocytes from EC and hippocampus. Previously we have demonstrated that $\mathrm{A} \beta$-oligomers affect the calcium signalling cascade in astrocytes derived from rat hippocampus, by increasing the expression of metabotropic glutamate receptor type 5 (mGluR5) and its downstream receptor, $\operatorname{InsP}_{3}$ receptor type 1 (InsP $\mathrm{P}_{3} \mathrm{R} 1$ ), which resulted in an increased amplitude of $\mathrm{Ca}^{2+}$ responses to selective mGluR5 agonist, DHPG. ${ }^{23}$ Here, we compared the effects of $\mathrm{A} \beta$ oligomers on the expression of 

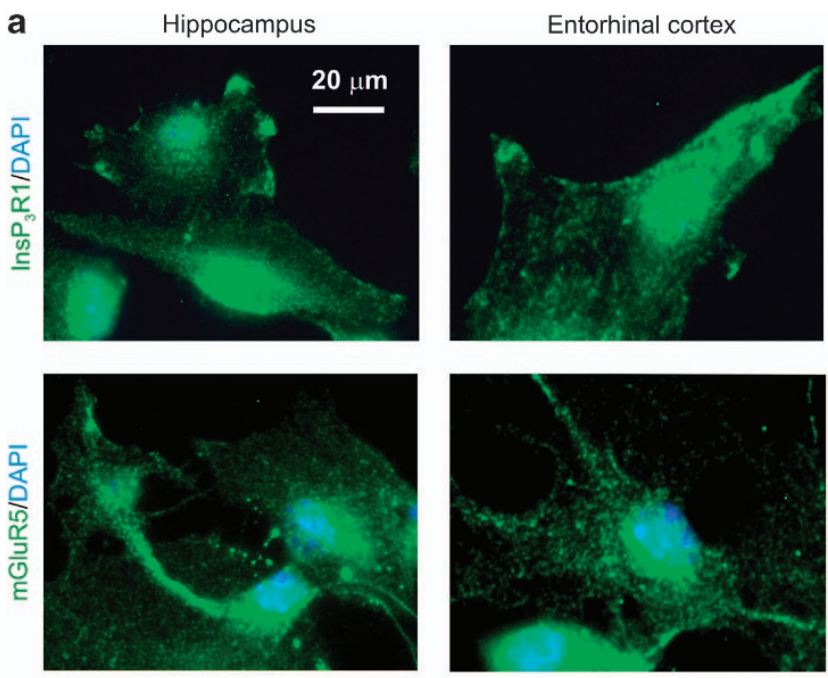

b
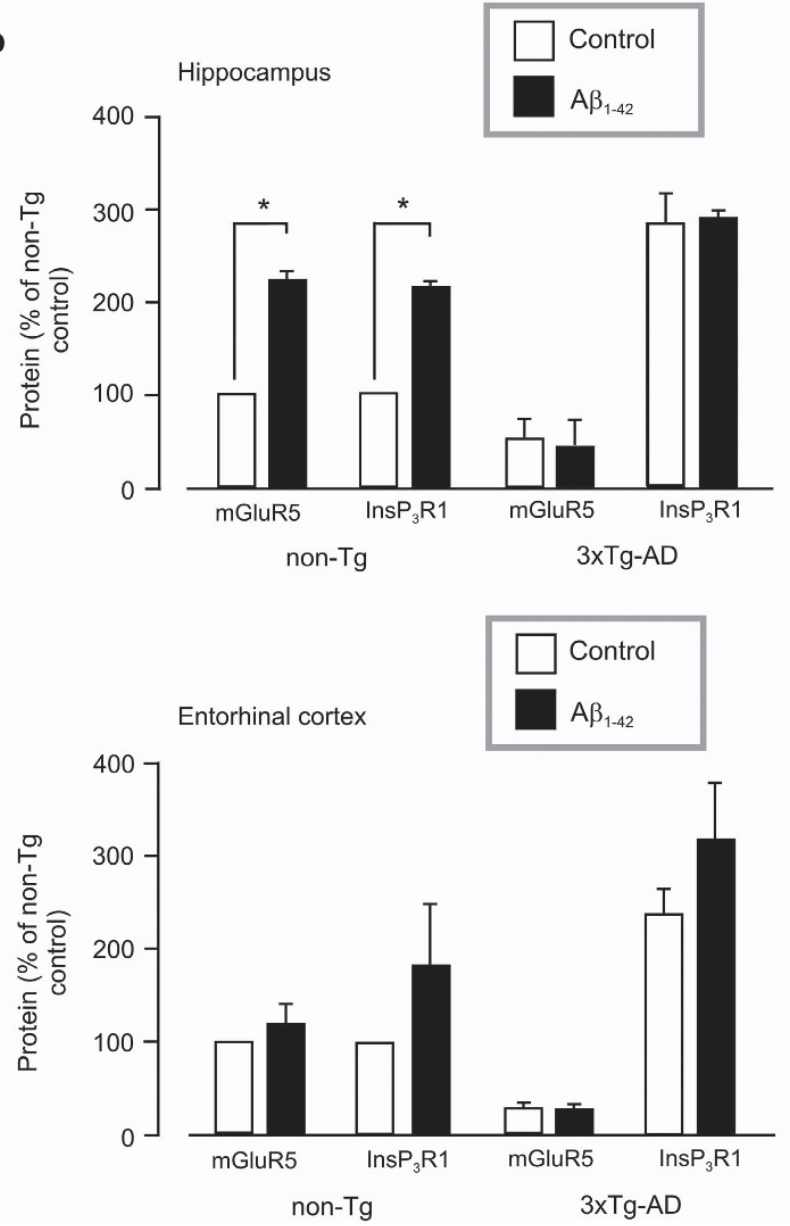

Figure $2 A \beta$ oligomers differentially affect the expression of mGluR5 and Ins $\mathrm{P}_{3} \mathrm{R} 1$ in astrocytes from different regions of the brain. (a) Representative immunostaining of mGluR5 and $\operatorname{Ins}_{3} \mathrm{R} 1$ (green) and DAPI-staining for nuclei (blue) in astrocytes cultured from EC and hippocampus of non-Tg mice at 7 days in vitro. (b) Quantifications of the expression (western blot analysis) of mGluR5 and InsP ${ }_{3} R 1$ expression in control cells and cells treated with $100 \mathrm{nM}$ of $\mathrm{A} \beta$ for $72 \mathrm{~h}$ in hippocampal cultures (upper graph) and EC cultures (lower graph) $\left({ }^{*} P<0.05\right.$, averages of seven cultures for non-Tg mice and four cultures for $3 \times \mathrm{Tg}$ $A D$ mice)
mGluR5 and $\operatorname{InsP}_{3} \mathrm{R} 1$ in astrocytes derived from the hippocampus and EC of 7-day-old non-Tg and 3xTg-AD mice.

First, we confirmed the presence of these receptors in astrocytes cultured from both the hippocampus and the EC of non-Tg control mice by immunocytochemistry (Figure 2a). Treatment with $100 \mathrm{nM} \mathrm{A} \beta_{1-42}$ induced strong and rapid upregulation of mGluR5 and $\operatorname{Ins}_{3} \mathrm{R} 1$ expression only in hippocampal astrocytes derived from non-Tg mice. This increase in receptor expression was already present after $48 \mathrm{~h}$ (data not shown), and was even more pronounced after $72 \mathrm{~h}$ of treatment (Figure $2 \mathrm{~b}$, upper panel).

In contrast, $A \beta$-treatment of astrocytes isolated from the $E C$ of non-Tg mice did not affect the expression of either mGluR5 or InsP $\mathrm{P}_{3} \mathrm{R} 1$ (Figure $2 \mathrm{~b}$, lower panel). Further, $\mathrm{A} \beta$-oligomers had no effect on the expression of both receptors in astrocytes isolated from the hippocampus and EC of 3xTg-AD mice, although the basal levels of these proteins were different. In both EC and hippocampal astrocytes obtained from these mice, basal expression of mGluR5 was lower, whereas that of Ins $\mathrm{P}_{3} \mathrm{R} 1$ was higher compared with non-Tg control mice (Figure 2b).

Metabotropic glutamatergic calcium signalling is differentially affected by $A \beta$ in EC and hippocampal astrocytes. The group I mGluR family is composed of two members (mGluR1 and mGluR5). Our previous study revealed that mGluR5 was the sole receptor responsible for DHPG-induced $\mathrm{Ca}^{2+}$ transients in astrocytes. ${ }^{23}$ Moreover, mGluR1 is either absent or present at low levels in these cells, as also has been observed by others. ${ }^{24,25}$

After treating the astrocytes from the EC and hippocampus of non-Tg and 3xTg-AD mice with $100 \mathrm{nM} \mathrm{A} \beta_{1-42}$ oligomers, cells were loaded with the calcium probe Fluo4-AM, and their responses to $100 \mathrm{nM}$ DHPG (15s) were analyzed. Figures $3 \mathrm{a}$ and $b$ show representative traces of DHPG-induced $\mathrm{Ca}^{2+}$ responses in astrocytes derived from the hippocampus and $\mathrm{EC}$ of non-Tg and $3 \mathrm{xTg}-\mathrm{AD}$ mice. Treatment with $\mathrm{A} \beta$ significantly increased the amplitude of DHPG-responses in hippocampal astrocytes when compared with control. The same treatment, however, did not modify $\mathrm{Ca}^{2+}$ responses in $\mathrm{EC}$ astrocytes derived from the same mice (Figure $3 \mathrm{~b}$ ). The integrals ('area under the curve') of $\left[\mathrm{Ca}^{2+}\right]_{i}$ transient that represent the overall $\mathrm{Ca}^{2+}$ load of stimulated cells were $26.20 \pm 5.77$ in non-Tg control hippocampal astrocytes versus $46.09 \pm 7.41$ in non- $\mathrm{Tg} \mathrm{A} \beta$-treated hippocampal astrocytes $(P<0.05)$, and $16.57 \pm 5.32$ in non-Tg control EC astrocytes versus $14.36 \pm 5.35$ in non-Tg $\mathrm{A} \beta$-treated $\mathrm{EC}$ astrocytes $(P=0.75)$ (Figure 3c, $n=150$ cells from five different cultures for each experimental protocol).

In astrocytes from $3 \times \mathrm{Tg}-\mathrm{AD}$ animals, $\mathrm{A} \beta$ oligomers did not affect the DHPG-mediated $\mathrm{Ca}^{2+}$ responses, neither in hippocampal nor in EC astrocytes (Figure 3c). The overall amplitudes of DHPG-induced $\mathrm{Ca}^{2+}$ responses in EC astrocytes were lower than in cells from the hippocampus $\left(\left[\mathrm{Ca}^{2+}\right]_{\mathrm{i}}\right.$ transient integral $28.65 \pm 5.76$ in $3 \times T$ Tg-AD control hippocampal astrocytes versus $24.51 \pm 9.33$ in $3 \times \mathrm{Tg}$-AD $\mathrm{A} \beta$-treated hippocampal astrocytes $(P=0.66)$; and $11.13 \pm 6.88$ in $3 \times T g-A D$ control EC astrocytes versus $18.70 \pm 8.25$ in 3xTg-AD-treated A $\beta$ EC astrocytes $(P=0.44), n=150$ cells from five cultures). 

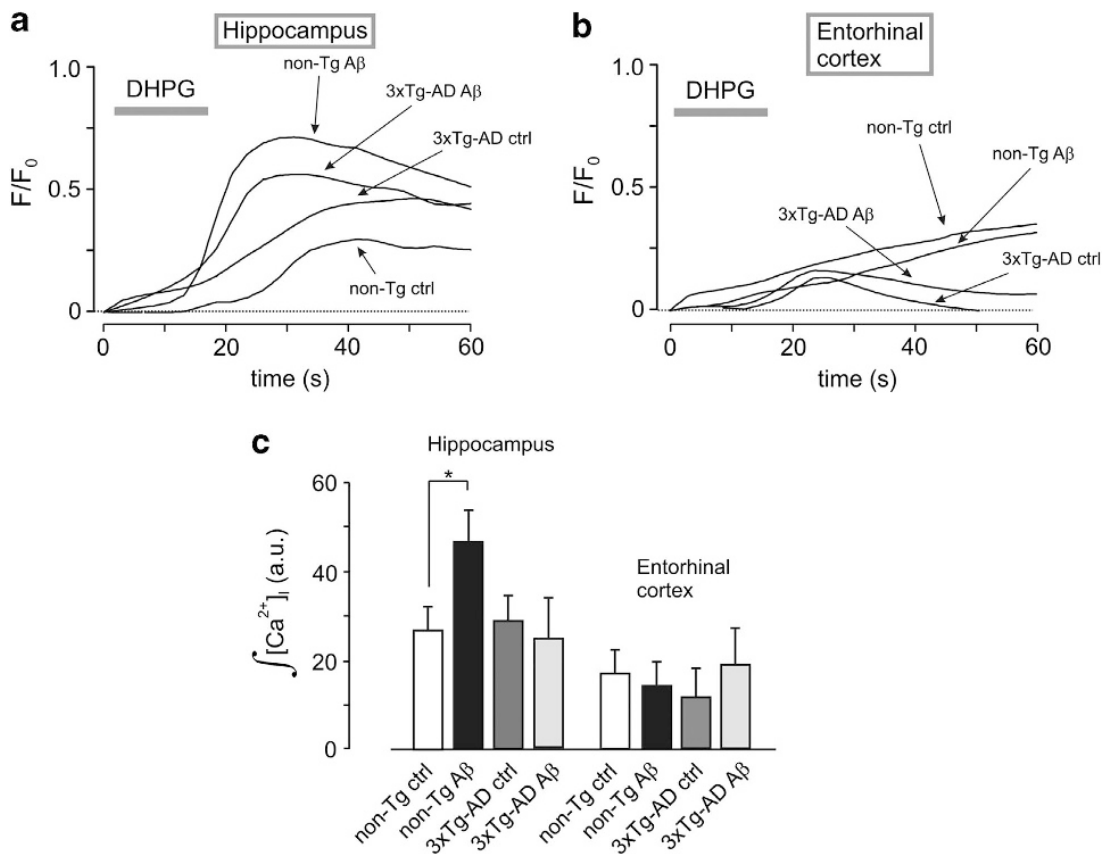

Figure 3 Effect of $A \beta$ treatment on metabotropic glutamatergic $\mathrm{Ca}^{2+}$ signalling in $\mathrm{EC}$ and hippocampal astrocytes from non- $\mathrm{Tg}$ and $3 \times \mathrm{Tg}-\mathrm{AD}$ mice. (a and $\mathbf{b}$ ) Representative traces of DHPG-induced $\mathrm{Ca}^{2+}$ responses in hippocampus and EC in control and in A $\beta$-treated cells derived from non-Tg mice, and control and $\mathrm{A} \beta$-treated cells derived from 3xTg-AD mice ( $n=30$ cells for each experimental protocol). The cells were exposed to $100 \mathrm{nM}$ of $\mathrm{A} \beta$ for $72 \mathrm{~h}$ and then loaded with Fluo4-AM, and stimulated with $100 \mu \mathrm{M} \mathrm{DHPG}$ for $15 \mathrm{~s}$. (c) Mean values for integrals of $\left[\mathrm{Ca}^{2+}\right]_{\mathrm{i}}$ transients induced by DHPG stimulation $(n=150$ cells from five different cultures for each experimental protocol)

Purinergic calcium signalling is differentially affected by $A \beta$ in $E C$ and hippocampal astrocytes. $\mathrm{Ca}^{2+}$ responses to ATP stimulation were examined in astrocytes from the EC and hippocampus subjected to $72 \mathrm{~h}$ of incubation with $\mathrm{A} \beta_{1-42}$ oligomers. Treatment with $\mathrm{A} \beta$ resulted in an increase of ATPinduced $\mathrm{Ca}^{2+}$ signals only in astrocytes isolated from the hippocampus of non- $\mathrm{Tg}$ mice compared to control cells (Figure 4). Mean values for integrals of $\left[\mathrm{Ca}^{2+}\right]_{i}$ transients were $15.30 \pm 1.50$ in non-Tg control hippocampal astrocytes versus $29.11 \pm 2.12$ in non- $T g A \beta$-treated hippocampal astrocytes $(P<0.01)$; and $9.64 \pm 3.68$ in non-Tg control EC astrocytes versus $19.60 \pm 6.56$ in non-Tg $A \beta$-treated $E C$ astrocytes ( $P=0.37) ; n=150$ cells from five cultures).

3xTg-AD hippocampal astrocytes showed basal calcium deregulation when stimulated with ATP. Treatment with $\mathrm{A} \beta$ did not affect ATP-induced $\mathrm{Ca}^{2+}$ responses in astrocytes from 3xTg-AD mice from both the EC and hippocampus (Figure 4; integrals of $\left[\mathrm{Ca}^{2+}\right]_{i}$ transients were $29.15 \pm 2.05$ in 3xTg-AD control hippocampal astrocytes versus $32.56 \pm 3.40$ in 3xTg-AD A $\beta$-treated hippocampal astrocytes $(P=0.34)$; and $15.75 \pm 6.57$ in $3 \times \mathrm{Tg}-\mathrm{AD}$ control EC astrocytes versus $30.79 \pm 11.98$ in $3 \times \mathrm{Tg}-\mathrm{AD} \quad \mathrm{A} \beta$-treated $\mathrm{EC}$ astrocytes $(P=0.36) ; n=120$ cells from four different cultures). However, in hippocampal astrocytes derived from 3xTg-AD mice, the amplitudes of ATP-calcium responses in control cells were significantly higher compared with that measured in astrocytes derived from non-Tg mice (Figure 4c, integrals of $\left[\mathrm{Ca}^{2+}\right]_{\mathrm{i}}$ transients being $15.30 \pm 1.50$ versus $29.15 \pm 2.05$, $P<0.01)$. In that, the amplitudes of ATP-mediated $\mathrm{Ca}^{2+}$ responses in hippocampal astrocytes derived from 3xTg-AD mice $\left(\left[\mathrm{Ca}^{2+}\right]_{\mathrm{i}} 29.15 \pm 2.05\right)$ were comparable to the amplitudes of ATP-mediated $\mathrm{Ca}^{2+}$ responses in $\mathrm{A} \beta$-treated hippocampal astrocytes derived from non-Tg mice $\left(\left[\mathrm{Ca}^{2+}\right]_{\mathrm{i}}\right.$ $29.11 \pm 2.12$ ). In contrast, there was little difference between the amplitudes of ATP-mediated $\mathrm{Ca}^{2+}$ responses in astrocytes from the EC of non-Tg mice and 3xTg-AD mice (Figure $4 \mathrm{c}$, integrals of $\left[\mathrm{Ca}^{2+}\right]_{\mathrm{i}}$ transients were $9.64 \pm 3.68$ versus $15.75 \pm 6.57, P=0.13$ ).

\section{Discussion}

In this study, we have investigated the effect of $A \beta$ oligomers on calcium signalling cascades in astrocytes derived from two brain regions predicted to be principally involved in $A D$ pathology, namely, the hippocampus and EC. The key findings presented in this paper are: (1) astrocytes derived from the hippocampus and EC retain their morphological phenotype in vitro for several days after isolation; (2) astrocytes from these two different regions have distinct $\mathrm{Ca}^{2+}$ signalling toolkits that are differentially affected by $\mathrm{A} \beta$-oligomers. Of particular interest are: (i) treatment of healthy astrocytes with $A \beta$ increased the expression of mGluR5 and $\operatorname{InsP}_{3} R 1$ only in hippocampal astrocytes; (ii) in agreement with this, $A \beta$ treatment potentiated $\mathrm{Ca}^{2+}$ responses mediated through $\mathrm{mGluR} / \mathrm{Ins} \mathrm{P}_{3} R$ s cascade only in hippocampal and not in EC astrocytes; and (iii) treatment with $\mathrm{A} \beta$ did not affect $\mathrm{Ca}^{2+}$ signalling in astrocytes isolated from the transgenic animal model of AD.

Our previous results showed a concomitant occurrence of astroglial atrophy, as a generalized process, and astrogliosis of the astrocytes surrounding senile plaques in hippocampus 

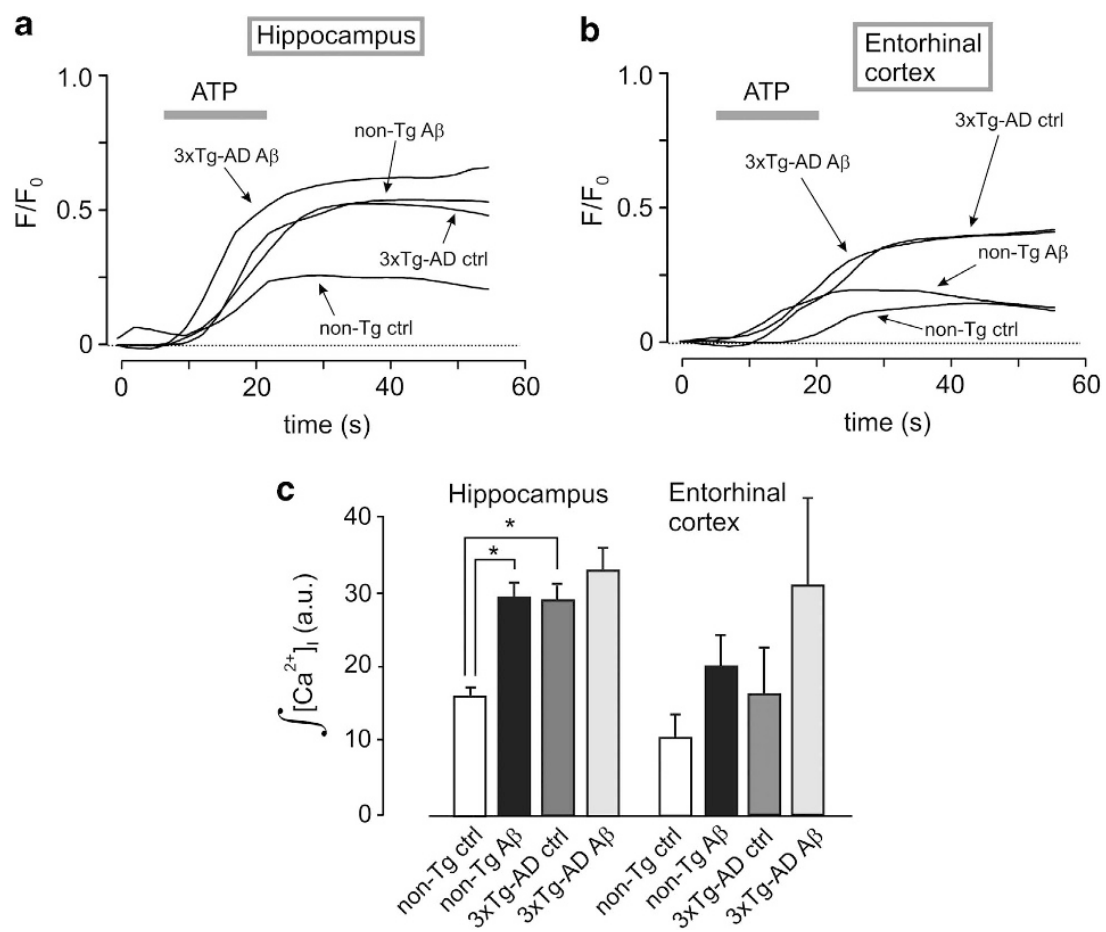

Figure 4 Effect of $\mathrm{A} \beta$ treatment on metabotropic purinergic $\mathrm{Ca}^{2+}$ signalling in $\mathrm{EC}$ and hippocampal astrocytes from non-Tg and $3 \times \mathrm{Tg}-\mathrm{AD}$ mice. (a and $\left.\mathbf{b}\right)$ Representative traces of ATP-induced $\mathrm{Ca}^{2+}$ responses in hippocampus and EC in control cells and in A $\beta$-treated cells derived from non-Tg mice, and control and $A \beta$-treated cells derived from 3xTg-AD mice ( $n=30$ cells for each experimental protocol). The cells were exposed to $100 \mathrm{nM}$ of $\mathrm{A} \beta$ for $72 \mathrm{~h}$ and then loaded with Fluo4-AM, and stimulated with $100 \mu \mathrm{M}$ ATP for $15 \mathrm{~s}$. (c) Mean values for integrals of $\left[\mathrm{Ca}^{2+}\right]_{i}$ transients induced by ATP stimulation ( $n=150$ cells from five different cultures for each experimental protocol)

of 3xTg-AD mice. ${ }^{15}$ Subsequently, we found that although the astroglial atrophy persisted in the EC and in the prefrontal cortex, the astrogliotic reaction in the EC was absent. ${ }^{22,26} \mathrm{We}$ failed to observe any signs of hypertrophy in EC astrocytes in both non-Tg and 3xTg-AD animals at all ages up to 18 months. The present study was designed to determine functional differences between astrocytes from different brain areas.

First, we confirmed in primary cell culture our previous in situ results, that astrocytes even after isolation from the brain retain their morphological idiosyncrasies for 3-5 days in vitro: astrocytes from the EC remained characteristically needle-shaped, whereas hippocampal astrocytes had more of a star-like appearance. Furthermore, we observed that overall percentage of stellate astroglial cells was higher in hippocampal cultures, which may be indicative of their higher intrinsic reactivity.

Different hypotheses are recognized for AD pathology, because of its multifactorial trait. One of them is the 'amyloid hypothesis', in which the main cause of AD is the deposition of amyloid- $\beta$ plaques (senile plaques) that disrupted the normal activity of neurons in the brain. ${ }^{27}$ Another hypothesis assumed the pathological role of abnormal $\mathrm{Ca}^{2+}$ homeostasis; this 'calcium hypothesis' of neurodegeneration ${ }^{28-33}$ postulates that $\mathrm{A} \beta$ affects calcium homeostasis/signalling in neurons that results in long-lasting overload of the cytoplasm with $\mathrm{Ca}^{2+}$ in parallel with disrupted $\mathrm{Ca}^{2+}$ handling by the endoplasmic reticulum, the two processes initiating metabolic and biosynthetic stress, ultimately leading to neuronal death. ${ }^{31,34,35}$
For these reasons, the present study was focused on calcium signalling pathways, which are critically involved in astroglial functions in health and disease. ${ }^{36}$ Disruption of $\mathrm{Ca}^{2+}$ homeostasis is implicated in many forms of neuropathology, ${ }^{37-40}$ and in particular $\mathrm{Ca}^{2+}$ deregulation is considered to be of fundamental importance for cellular pathology in $\mathrm{AD} .^{31,32,35,41}$ The key pathway of astroglial $\mathrm{Ca}^{2+}$ signalling is represented by a metabotropic route that comprises seven transmembrane domain $\mathrm{G}$ protein-coupled receptors (of which glutamate and purinoceptors are the most abundant in glia), phospholipase $\mathrm{C}$ and Ins $\mathrm{P}_{3} \mathrm{Rs}$ located at the endomembrane. ${ }^{36}$

We established that treatment with pathologically relevant (100 nM) concentrations of $\mathrm{A} \beta$ affects the metabotropic $\mathrm{Ca}^{2+}$ signalling toolkit in $\mathrm{EC}$ and hippocampal astrocytes in a very different way. Exposure to $A \beta$ increased the expression of both mGluR5 and Ins $\mathrm{P}_{3} \mathrm{R} 1$ in hippocampal astrocytes. This increase in expression of $\mathrm{Ca}^{2+}$ signalling molecules resulted in an increase in the amplitude of $\left[\mathrm{Ca}^{2+}\right]_{i}$ transients following stimulation with mGluR5 agonist DHPG or ATP. In contrast, treatment with $\mathrm{A} \beta$ neither affected expression of metabotropic $\mathrm{Ca}^{2+}$ signalling toolkit, nor modified the parameters of DHPG and ATP-induced $\mathrm{Ca}^{2+}$ transients in EC astrocytes.

Of significance, the effects of $\mathrm{A} \beta$ treatment changed completely in a pathological context in that exposure of EC and hippocampal astrocytes derived from 3xTg-AD animals to $\mathrm{A} \beta$ affected neither expression of mGluR5 and InsP $\mathrm{P}_{3} \mathrm{R} 1$, nor the parameters of metabotropically stimulated $\left[\mathrm{Ca}^{2+}\right]_{i}$ transients. At the same time, basal levels of expression of 
mGluR5 and $\operatorname{InsP}_{3} \mathrm{R} 1$ were substantially modified in pathologically remodelled astrocytes compared with non-transgenic controls. Similarly, stimulation of astrocytes with agonists triggered $\left[\mathrm{Ca}^{2+}\right]_{i}$ transients with higher amplitudes compared with cells from healthy wild-type controls. We can therefore suggest that expression of $A D$-related mutant genes deregulates $\mathrm{Ca}^{2+}$ homeostasis and signalling in astroglia.

In conclusion, we have shown that astrocytes from different brain regions display different patterns of response to exogenous $\mathrm{A} \beta$. This transpires to different responses of the $\mathrm{Ca}^{2+}$ signalling toolkit to a pathological context and may account for the different reactivities of astroglia observed in the whole tissue to the progression of $A D$. We may therefore speculate that the distinct responsiveness of $\mathrm{Ca}^{2+}$ signalling machinery in EC astrocytes can be linked to their inability to mount astrogliotic response to $\beta$-amyloid deposition, which in turn can underlie the higher vulnerability of $E C$ to $A D$-like pathology. This far-reaching speculation naturally requires future experiments and, above all, analysis of $\left[\mathrm{Ca}^{2+}\right]_{i}$ signalling in astrocytes from different brain regions in situ and in vivo.

\section{Materials and Methods}

All animal procedures were carried out in accordance with the United Kingdom Animals (Scientific Procedures) Act of 1986 under the license from Home Office. All efforts were made to reduce the number of animals by following the 3 R's.

Animal models. Experiments were performed on 3xTg-AD mice, introduced by Frank LaFerla and Salvatore Oddo in $2003 .^{42}$ These mice were developed on the mixed 129/C57BL6 background and harbor APP $_{\text {swe, }}$ PS1M146V and TauP301L mutations. The 3xTg-AD animals show major hallmarks of $A D$ represented by senile plaques and neurofibrillary tangles. The non- $\mathrm{Tg}$ (nontransgenic) control mice were from the same strain and the same genetic background. All 3xTg-AD and non-Tg littermates were from homozygous breeders.

Primary astrocyte cultures and $\mathbf{A} \beta$ treatment. The EC and hippocampus were dissected from the brains of 7-day-old non- $T g$ and $3 x T g-A D$ mice. Purified glial cell cultures were prepared as described previously. ${ }^{43}$ Isolated astrocytes were seeded in Dulbecco's modified Eagle's medium (DMEM) with $4.5 \mathrm{~g} / \mathrm{l}$ D-glucose (Gibco 11960-044; Life Sciences Ltd, Paisley, UK), supplemented with $10 \%$ fetal bovine serum (FBS), $2 \mathrm{mg} / \mathrm{ml}$ glutamine, $10 \mathrm{U} / \mathrm{ml}$ penicillin and $100 \mu \mathrm{g} / \mathrm{ml}$ streptomycin (Sigma, Dorset, UK). The cells were grown until confluence (2-4 days) and then were plated on coverslips coated with $0.1 \mathrm{mg} /$ $\mathrm{ml}$ poly-L-lysine. The purity of cultures was assayed by immunostaining with antiMAP2 (neuronal marker) and anti-GFAP (glial marker) and anti-lba1 (microglial marker). Both neurons and microglia accounted for $<0.5 \%$ of all cells.

Astrocytes were treated after 4 days in vitro (DIV) with $100 \mathrm{nM}$ of $\mathrm{A} \beta_{1-42}$ oligomers for 48 or $72 \mathrm{~h}$, and then analyzed by calcium imaging or western blot. As negative controls, we used an inactive form of amyloid protein $A \beta_{1-42}(100 \mathrm{nM})$ and vehicle (physiological saline); neither had any effect on expression of components of the $\mathrm{Ca}^{2+}$ signalling toolkit and parameters of $\mathrm{Ca}^{2+}$ signals.

Preparation of $\mathbf{A} \beta_{1-42}$ oligomers. $A \beta_{1-42}$ peptide was oligomerized as described previously, ${ }^{44}$ with some modifications. Briefly, $1 \mathrm{mg}$ of $A \beta$ was diluted in $1 \mathrm{ml}$ of 1,1,1,3,3,3-hexa-fluoro-2-propanol (HFIP, 52512 Fluka, Sigma) and incubated for $1 \mathrm{~h}$ at $37^{\circ} \mathrm{C}$. Then, HFIP was lyophilized by using a SpeedVac concentrator (Thermo Fisher Scientific, Loughborough, UK). The A $\beta$ pellet was subsequently dissolved in $5 \mathrm{mM}$ DMSO and then diluted to $100 \mu \mathrm{M}$ in ice-cold cell phosphate buffer. The solution was incubated overnight at $4^{\circ} \mathrm{C}$, which favoured oligomerization. Aliquots were stored at $-20^{\circ} \mathrm{C}$. The presence of oligomers was verified by loading the $A \beta$ preparation in a native gel stained with Coomassie.

Immunocytochemistry. Cultured astrocytes were fixed in $4 \%$ formaldehyde in PBS for $7 \mathrm{~min}$ at room temperature. Subsequently, primary and secondary antibodies were applied in GDB buffer, as described previously. ${ }^{45}$ Fluorescence images were acquired using a Zeiss Axiovert 25 microscope equipped with a Zeiss Axiocam HRc camera (Carl Zeiss Ltd, Welwyn Garden City, UK). Green fluorescence was detected at $515-565 \mathrm{~nm}$ following excitation at $450-490 \mathrm{~nm}$; red fluorescence was detected at $590 \mathrm{~nm}$ following excitation at $546 \mathrm{~nm}$; blue fluorescence was detected at $397 \mathrm{~nm}$ following excitation at $365 \mathrm{~nm}$. Phasecontrast images were obtained with the same microscopy setup.

Western blotting analysis. $1.0 \times 10^{6}$ cells were scraped and lysed in Lysis buffer composed of $20 \mathrm{mM}$ HEPES, $100 \mathrm{mM} \mathrm{NaCl}, 5 \mathrm{mM}$ EDTA, $1 \% \mathrm{NP}-40$ + Halt Protease \& Phosphatase Inhibitor Cocktail (Thermo Scientific, Fisher Scientific, Loughborough, UK). Protein quantification was performed with Bio-Rad Protein Assay (Bio-Rad, Hemel Hempstead, UK) and $50 \mu \mathrm{g}$ of proteins was resolved on 5-10\% gradient SDS-PAGE. Densitometric analysis was performed with Quantity One program (Bio-Rad).

Calcium imaging. Cells were loaded with $3 \mu \mathrm{M}$ of Fluo4-AM in Krebs-Ringer modified buffer (KRB) (136 mM NaCl, $20 \mathrm{mM}$ HEPES, $5.5 \mathrm{mM}$ glucose, $1.2 \mathrm{mM}$

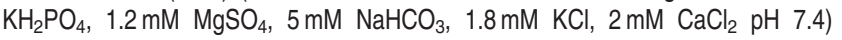
supplemented with $0.01 \%$ pluronic acid for $30 \mathrm{~min}$ at $37^{\circ} \mathrm{C}$. After de-esterification $\left(30 \mathrm{~min}\right.$ at $37^{\circ} \mathrm{C}$ ), the coverslips were placed in a perfusing chamber, mounted on the stage of an inverted confocal microscope (Nikon Eclipse TE300: Nikon Instruments Europe BV, Amstelveen, Netherlands). Cells were superfused with $\mathrm{KRB}$ at $8 \mathrm{ml} / \mathrm{min}$ and maintained at $37^{\circ} \mathrm{C}$. Cells were excited at $488 \mathrm{~nm}$ excitation laser (emitted light filtered at $515 \pm 30 \mathrm{~nm}$ ) and viewed using a $\times 20$ dry objective (NA 0.5). Fluorescent images were taken from the middle of the cell volume, and time series acquisition was controlled with EZ-C1 Nikon software. Drugs were applied by superfusion. To quantify the differences in the peaks of $\mathrm{Ca}^{2+}$ transients, the values were normalized using the formula $\left(F_{\mathrm{i}}-F_{0}\right) / F_{0}$ (where $F_{\mathrm{i}}$ is the value of fluorescence recorded during the stimulation and $F_{0}$ is the basal value of fluorescence recorded).

Reagents. Amyloid $\beta$ protein (1-42) hydrochloride salt (H-6466) was purchased from Bachem AG (Budendorf, Switzerland). Rabbit polyclonal antibody anti-InsP ${ }_{3} \mathrm{R} 1$ (AB5882) and rabbit polyclonal antibody anti-mGluR5 (AB5675) were from Millipore (Walford, UK); goat antibody anti-GFAP (SAB2500462) and adenosine triphosphate (ATP) were from Sigma; anti- $\beta$ - actin HRP-conjugated antibody from Santa Cruz Biotechnology (Heidelberg, Germany), Sc-47778 HRP; peroxidase-conjugated secondary antibodies were from GE Healthcare (Bucks, UK); (S)-3,5-dihydroxyphenylglycine (DHPG) was from Tocris Bioscience (Bristol, UK); Fluo4-AM calcium probe (F14201) and Pluronic F-127 (P3000MP) were from Invitrogen (Paisley, UK).

Statistical analysis. For multiple comparisons ANOVA analysis was used with Prism Graph Pad software. Between two groups Student's $t$-test or one-sample $t$-test was used. Differences were considered significant at $P<0.05$.

\section{Conflict of Interest}

The authors declare no conflict of interest.

Acknowledgements. We thank Sarah Lawton for technical help. The work has been supported by grant 2008-2319 from Fondazione Cariplo, by The Welcome Trust and by The Alzheimeŕs Research Trust (UK). Support from the Spanish Government, Plan Nacional de I+D I 2008-2011 and ISCIIISubdirección General de Evaluación y Fomento de la Investigación (PI10/02738) co-financed by FEDER to JJR and AV as well as the Government of the Basque Country (AE-2010-1-28, AEGV10/16, GV-2011111020) to JJR are gratefully acknowledged.

1. Verkhratsky A, Sofroniew MV, Messing A, deLanerolle NC, Rempe D, Rodriguez JJ et al. Neurological diseases as primary gliopathies: a reassessment of neurocentrism. ASN Neurol 2012; 4: e00082.

2. Giaume $C$, Kirchhoff $F$, Matute $C$, Reichenbach A, Verkhratsky A. Glia: the fulcrum of brain diseases. Cell Death Differ 2007; 14: 1324-1335.

3. Virchow R. Die Cellularpathologie in ihrer Begründung auf physiologische and pathologische Gewebelehre. Zwanzig Vorlesungen gehalten während der Monate Februar, März und April 1858 im pathologischen Institut zu Berlin.. 1st edn. August Hirschwald: Berlin, 1858. 
4. Kettenmann H, Verkhratsky A. Neuroglia: the 150 years after. Trends Neurosci 2008; 31 653-659.

5. Alzheimer A. Beiträge zur Kenntnis der pathologischen Neuroglia und ihrer Beziehungen zu den Abbauvorgängen im Nervengewebe. In: Nissl F, Alzheimer A (eds) Histologische und histopathologische Arbeiten über die Grosshirnrinde mit besonderer Berücksichtigung der pathologischen Anatomie der Geisteskrankheiten vol. 1-3 (Gustav Fischer: Jena, 1910. , pp 401-562.

6. Heneka MT, Rodriguez JJ, Verkhratsky A. Neuroglia in neurodegeneration. Brain Res Rev 2010; 63: 189-211.

7. Messing A, Brenner M, Feany MB, Nedergaard M, Goldman JE. Alexander disease. J Neurosci 2012; 32: 5017-5023.

8. Rossi D, Volterra A. Astrocytic dysfunction: insights on the role in neurodegeneration. Brain Res Bull 2009; 80: 224-232.

9. Rodriguez JJ, Olabarria M, Chvatal A, Verkhratsky A. Astroglia in dementia and Alzheimer's disease. Cell Death Differ 2009; 16: 378-385.

10. Braak E, Griffing K, Arai K, Bohl J, Bratzke H, Braak H. Neuropathology of Alzheimer's disease: what is new since A. Alzheimer? Eur Arch Psychiatry Clin Neurosci 1999; 249(Suppl 3): 14-22.

11. Palop JJ, Mucke L. Amyloid- $\beta$-induced neuronal dysfunction in Alzheimer's disease: from synapses toward neural networks. Nat Neurosci 2010; 13: 812-818.

12. Sheng M, Sabatini BL, Sudhof TC. Synapses and Alzheimer's disease. Cold Spring Harbor Perspect Biol 2012; 4: a005777

13. Mucke L, Selkoe DJ. Neurotoxicity of amyloid $\beta$-Protein: synaptic and network dysfunction. Cold Spring Harb Perspect Med 2012; 2: a006338.

14. Terry RD. Cell death or synaptic loss in Alzheimer disease. J Neuropathol Exp Neurol 2000; 59: 1118-1119.

15. Olabarria M, Noristani HN, Verkhratsky A, Rodriguez JJ. Concomitant astroglial atrophy and astrogliosis in a triple transgenic animal model of Alzheimer's disease. Glia 2010; 58 : 831-838.

16. Verkhratsky A, Olabarria M, Noristani HN, Yeh CY, Rodriguez JJ. Astrocytes in Alzheimer's disease. Neurotherapeutics 2010; 7: 399-412.

17. Lipton PA, Eichenbaum H. Complementary roles of hippocampus and medial entorhinal cortex in episodic memory. Neural Plasticity 2008; 2008: 258467.

18. van Groen T, Miettinen P, Kadish I. The entorhinal cortex of the mouse: organization of the projection to the hippocampal formation. Hippocampus 2003; 13: 133-149.

19. Gomez-Isla T, Price JL, McKeel DW Jr., Morris JC, Growdon JH, Hyman BT. Profound loss of layer II entorhinal cortex neurons occurs in very mild Alzheimer's disease. J Neurose 1996; 16: 4491-4500.

20. Roberts GW, Nash M, Ince PG, Royston MC, Gentleman SM. On the origin of Alzheimer's disease: a hypothesis. Neuroreport 1993; 4: 7-9.

21. Lazarov O, Lee M, Peterson DA, Sisodia SS. Evidence that synaptically released $\beta$-amyloid accumulates as extracellular deposits in the hippocampus of transgenic mice. J Neurosci 2002; 22: 9785-9793.

22. Yeh CY, Vadhwana B, Verkhratsky A, Rodriguez JJ. Early astrocytic atrophy in the entorhinal cortex of a triple transgenic animal model of Alzheimer's disease. ASN Neurol 2012; 3: 271-279.

23. Grolla AA, Fakhfouri G, Balzaretti G, Marcello E, Gardoni F, Canonico PL et al. A $\beta$ leads to $\mathrm{Ca}^{2+}$ signaling alterations and transcriptional changes in glial cells. Neurobiol Aging 2013; 34: $511-522$

24. Nakahara K, Okada M, Nakanishi S. The metabotropic glutamate receptor mGluR5 induces calcium oscillations in cultured astrocytes via protein kinase $C$ phosphorylation. J Neurochem 1997; 69: 1467-1475.
25. Schools GP, Kimelberg HK. mGluR3 and mGluR5 are the predominant metabotropic glutamate receptor mRNAs expressed in hippocampal astrocytes acutely isolated from young rats. J Neurosci Res 1999; 58: 533-543.

26. Kulijewicz-Nawrot M, Verkhratsky A, Chvatal A, Sykova E, Rodriguez JJ. Astrocytic cytoskeletal atrophy in the medial prefrontal cortex of a triple transgenic mouse model of Alzheimer's disease. J Anat 2012; 221: 252-262.

27. LaFerla FM, Green KN, Oddo S. Intracellular amyloid- $\beta$ in Alzheimer's disease. Nat Rev Neurosci 2007; 8: 499-509.

28. Khachaturian ZS. Calcium, membranes, aging, and Alzheimer's disease. Introduction and overview. Ann New York Acad Sci 1989; 568: 1-4

29. Khachaturian ZS. Hypothesis on the regulation of cytosol calcium concentration and the aging brain. Neurobiol Aging 1987; 8: 345-346.

30. Verkhratsky A, Toescu EC. Calcium and neuronal ageing. Trends Neurosci 1998; 21: 2-7.

31. Stutzmann GE. The pathogenesis of Alzheimers disease is it a lifelong 'calciumopathy'? Neuroscientist 2007; 13: 546-559.

32. Berridge MJ. Calcium hypothesis of Alzheimer's disease. Pflugers Arch 2010; 459: 441-449.

33. Green KN, Smith IF, Laferla FM. Role of calcium in the pathogenesis of Alzheimer's disease and transgenic models. Sub-Cell Biochem 2007; 45: 507-521.

34. Demuro A, Parker I, Stutzmann GE. Calcium signaling and amyloid toxicity in Alzheimer disease. J Biol Chem 2010; 285: 12463-12468.

35. Supnet $\mathrm{C}$, Bezprozvanny I. The dysregulation of intracellular calcium in Alzheimer disease. Cell Calcium 2010; 47: 183-189.

36. Verkhratsky A, Rodriguez JJ, Parpura V. Calcium signalling in astroglia. Mol Cell Endocrinol 2012; 353: 45-56.

37. Nedergaard M, Rodriguez JJ, Verkhratsky A. Glial calcium and diseases of the nervous system. Cell Calcium 2010; 47: 140-149.

38. Stutzmann GE, Mattson MP. Endoplasmic reticulum $\mathrm{Ca}^{2+}$ handling in excitable cells in health and disease. Pharmacol Rev 2011; 63: 700-727.

39. Surmeier DJ, Guzman JN, Sanchez-Padilla J. Calcium, cellular aging, and selective neuronal vulnerability in Parkinson's disease. Cell Calcium 2010; 47: 175-182.

40. Szydlowska K, Tymianski M. Calcium, ischemia and excitotoxicity. Cell Calcium 2010; 47: 122-129.

41. Toescu EC, Verkhratsky A. The importance of being subtle: small changes in calcium homeostasis control cognitive decline in normal aging. Aging Cell 2007; 6: 267-273.

42. Oddo S, Caccamo A, Shepherd JD, Murphy MP, Golde TE, Kayed R et al. Tripletransgenic model of Alzheimer's disease with plaques and tangles: intracellular $A \beta$ and synaptic dysfunction. Neuron 2003; 39: 409-421

43. Fresu L, Dehpour A, Genazzani AA, Carafoli E, Guerini D. Plasma membrane calcium ATPase isoforms in astrocytes. Glia 1999; 28: 150-155.

44. Giuffrida ML, Caraci F, Pignataro B, Cataldo $\mathrm{S}$, De Bona $\mathrm{P}$, Bruno V et al. $\beta$-amyloid monomers are neuroprotective. J Neurosci 2009; 29: 10582-10587.

45. Sala C, Piech V, Wilson NR, Passafaro M, Liu G, Sheng M. Regulation of dendritic spine morphology and synaptic function by Shank and Homer. Neuron 2001; 31: 115-130.

(c) () $\odot$ Cell Death and Disease is an open-access journal published by Nature Publishing Group. This work is licensed under a Creative Commons Attribution-NonCommercialNoDerivs 3.0 Unported License. To view a copy of this license, visit http://creativecommons.org/licenses/by-nc-nd/3.0/ 